\title{
Can fetal ossicles be used as prosthesis in adults? A morphometric study*
}

\author{
Gulrez Nadeem \\ College of Dentistry, Ajman University of Science and Technology, Ajman, UAE
}

\begin{abstract}
Objectives: The tympanic cavity contains 3 small immovable bones, the malleus, incus and stapes. Extensive studies have been carried out on the morphometry of the ossicles. According to some scientists, in human beings the auditory ossicles reach there definitive size and shape in fetal periods and postnatal modifications are minimal, while there are certain studies which their contradict this claim. These contradictory claims prompted us to make an endeavor to find out the growth pattern of the ear ossicles and comparing the data with adults.

Methods: Twenty-two fetal cadavers of either sex, ranging in gestational ages between 24-40 weeks, were collected from local hospitals and 15 adult formalin-fixed cadavers in age groups of 20-30 years were taken. For the study, the fetuses were kept in 2 Groups of 24-28 weeks and 36-40 weeks. From the data obtained, the mean, standard deviation and percentage gain from one group to another in different dimensions of various parts of each ossicle was calculated.

Results: The age periods between 40 weeks (full term fetuses) and adults, revealed spurt in the growth of diameter of head of malleus $(3 \%)$, width of short process of incus $(2.7 \%)$, width of footplate $(5.2 \%)$ and height of stapes (13\%). These changes were insignificant in terms of acoustic transmission.

Conclusion: It is concluded that by the end of gestation, the ear ossicles develop morphometric features comparable to adults with no appreciable changes in the post natal period. Hence, they can be used as prosthesis in adults suffering from ossicular chain malformations and can be an easy and cheap method for treatment of this type of patients.
\end{abstract}

Key words: ear ossicles; incus; malleus; morphometry; stapes

Anatomy 2012-2013;6-7:52-57, (C) 2012-2013 TSACA

\section{Introduction}

The tympanic cavity contains 3 small immovable bones, the malleus, incus and stapes. The auditory ossicles extend like a chain across the tympanic cavity to connect functionally the tympanic membrane with the vestibular (oval) window. The lateral ossicle is the malleus, firmly attached to the tympanic membrane, most medial is the stapes which is fixed to the vestibular window and is in direct contact with the fluid perilymph, the intermediate between the two lies the incus. These three bones are bound together by articulations, and they also effect ligamentous connections with the walls of containing cavi- ty. The compound osseous system acts like a bent lever to connect the vibrations of the tympanic membrane into intensified thrusts of stapes against the perilymph. ${ }^{[1]}$

Extensive studies have been carried out on the morphometry of human ossicles, ${ }^{[2-5]}$ anomalies of the ossicles, ${ }^{[6-10]}$ embryology ${ }^{[1]]}$ and structure and function of the ossicles. ${ }^{[12-14]}$ Most of these studies were done on adult ossicles and have been studied on European populations, who have mesaticephalic type of skulls, but the present study has been done on Indian skulls that have dolichocephalic skulls. ${ }^{[15]}$ Thus, this is one of the aspects of justifying the utility of the study. 
Accordingly in human beings the auditory ossicles reach there definitive size and shape in fetal periods and postnatal modifications are minimal. ${ }^{[16]}$ Similar findings were reported that auditory ossicles reach their adult size in fetus by 6 months intrauterine length (IUL). ${ }^{[17]}$ Then some studies also documented the presence of adult sized ossicles in human fetuses of 5 th month IUL and that their development is not fixed to rate of body growth in general. ${ }^{[18]}$

However, there are certain studies which contradict this claim. A study reported that the development of auditory ossicles in humans is not completed during fetal life. The different parameters in the fetal periods increased adequately in the post natal life. ${ }^{[19]}$

These contradictory claims prompted us to make an endeavor to find out the growth pattern of the ear ossicles and comparing the data with adults.

\section{Materials and Methods}

Material for the study comprised 22 fetal and 15 adult cadavers. This study was done in the Department of Anatomy, Jawaharlal Nehru Medical College (JNMC), Aligarh Muslim University (AMU), Aligarh, Uttar Pradesh, India. The fetuses were obtained from D/0 Obstetrics and Gynecology, JNMC, AMU. The adult cadavers were obtained from the mortuary of $\mathrm{D} / 0$ Anatomy JNMC, AMU. The ossicles were obtained from tympanic cavity by opening the tegmen tympani. The measurements were made by screw gauge (leastcount-0.005). Photographs were taken by stereoscopic microscope and other guidelines for standard photography were taken. ${ }^{[20]}$

Gestational age of fetuses was determined by crownrump length using following the formula which states: ${ }^{[15]}$

For the first 5 months, age of fetus in lunar months = length of fetus in $\mathrm{cm}$

For the last 5 months, age of fetus in lunar months = length of fetus $/ 5$

The fetuses were divided in to 2 groups (Groups I and II) of 12 and 10 fetuses in each group, respectively. Group I included fetuses of gestational age 24-28 weeks IUL and Group II contained of fetuses ranging from 3640 weeks IUL.

Formula used for calculating the percentage gain between groups is: Difference of mean value in the 2 groups / Mean value of the preceding group x100

\section{Error of measurement}

In the present study, the measurement of error is done using 2 measures. They are technical error of measure- ment (TEM) and coefficient of reliability (R). ${ }^{[21-23]}$ The Formula for them are:

TEM=D/2N, where $\mathrm{D}$ denotes the difference between measurements (range) and $\mathrm{N}$ is the number of samples measured in that Groupe. $\mathrm{g}$ in this study Group I has 12 samples, Group II has 10 samples and adult group has 15 .

$\mathbf{R}=\mathbf{T E M} / \mathbf{S D}$, where SD is the total inter sample variance or the standard deviation in that group. It ranges between 0 and 1 . This coefficient reveals what proportion of the between sample variance in a group is free from measurement error e.g. an $\mathrm{R}$ value of 0.9 , means $90 \%$ of the variance is due to factors other than measurement error.

The following parameters of each ossicle were recorded:

Malleus

- Length of malleus (mm)

- Diameter of head (mm)

- Length of handle (mm)

Incus

- Total width of ossicle (mm)

- Length of body (mm)

- Length of long process (mm)

\section{Stapes}

- Length of base of foot plate (mm)

- Width of base of foot plate (mm)

- Height of ossicle (mm)

\section{Results}

\section{Malleus (Tables 1-3, Figure 1)}

Length of ossicle shows appreciable change during 28-36 weeks IUL of $+1.3 \%$. The ossicle attained a length of $97 \%$ of adult value at 6 months IUL and $98.2 \%$ at 9 months IUL.

Diameter of head shows fast growth rate between Groups I and II of $+5.4 \%$. It also achieved $92.5 \%$ of adult value at 6 th month IUL and $97.5 \%$ at 9 th month IUL.

Length of handle shows a steady growth with $+1.79 \%$ gain from Groups I and II. It assumed $97.1 \%$ of adult value at 6 th month IUL and $98.9 \%$ of adult value at 9 th month IUL.

\section{Incus (Tables 4-6, Figure 2)}

Length of ossicle shows an increment of $+5.2 \%$ between Groups I and II and this dimension achieved $92.7 \%$ of adult size at 6 th months IUL and $97.6 \%$ at 9 th month IUL. 
Table 1

Malleus: length of ossicle ( $\mathrm{mm}$ )

\begin{tabular}{lccccc}
\hline Group & Range & Mean \pm SD & TEM & R & $\%$ change \\
\hline I & $7.73-7.81$ & $7.76 \pm 0.03$ & 0.0030 & 0.90 & +1.3 \\
II & $7.83-7.90$ & $7.86 \pm 0.025$ & 0.0035 & 0.86 & \\
Adult & $7.95-8.30$ & $8.00 \pm 0.046$ & 0.0116 & 0.74 & +1.7 \\
\hline
\end{tabular}

Table 2

Malleus: diameter of head ( $\mathrm{mm})$

\begin{tabular}{lccccc}
\hline Group & Range & Mean \pm SD & TEM & R & $\%$ change \\
\hline I & $2.20-2.28$ & $2.22 \pm 0.027$ & 0.0033 & 0.87 & \\
II & $2.31-2.36$ & $2.34 \pm 0.02$ & 0.0021 & 0.93 & $+5.4 \%$ \\
Adult & $2.36-2.46$ & $2.40 \pm 0.03$ & 0.0050 & 0.83 & $+2.5 \%$ \\
\hline
\end{tabular}

Table 3

Malleus: length of handle $(\mathrm{mm})$

\begin{tabular}{lccccc}
\hline Group & Range & Mean \pm SD & TEM & R & $\%$ change \\
\hline I & $4.43-4.48$ & $4.45 \pm 0.02$ & 0.0021 & 0.89 & \\
II & $4.50-4.55$ & $4.53 \pm 0.018$ & 0.0025 & 0.86 & $+1.79 \%$ \\
Adult & $4.51-4.63$ & $4.58 \pm 0.015$ & 0.0040 & 0.73 & $+1.10 \%$ \\
\hline
\end{tabular}

Total width of ossicle shows appreciable change between Groups I and II of $+3.42 \%$. This parameter achieved $95.2 \%$ of adult size at 6 th month IUL and $98.4 \%$ at 9 th month IUL.

Length of long process show maximum increment between Groups I and II i.e. $+2.1 \%$, thus achieving

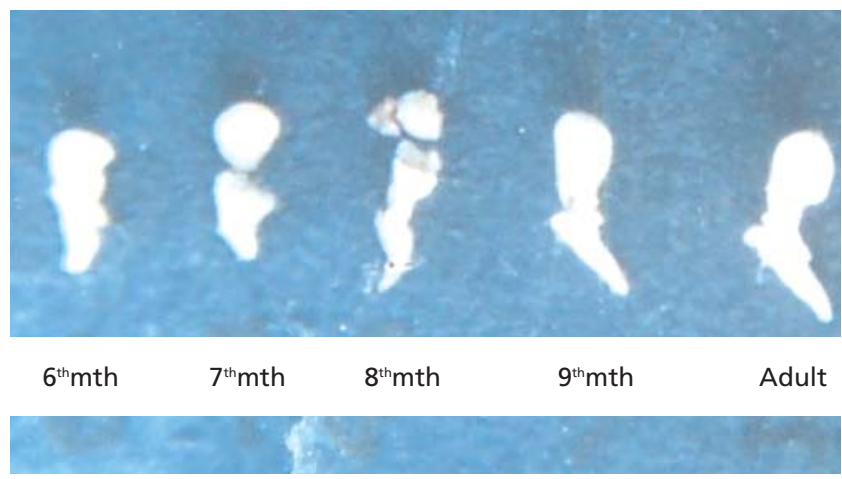

Figure 1. Human fetal malleus from 6th month to 9th month IUL and adult malleus.
Table 4

Incus: length of ossicle (mm)

\begin{tabular}{lccccc}
\hline Group & Range & Mean \pm SD & TEM & R & $\%$ change \\
\hline I & $5.83-6.05$ & $5.92 \pm 0.027$ & 0.0091 & 0.66 & \\
II & $6.15-6.32$ & $6.23 \pm 0.025$ & 0.0085 & 0.66 & $+5.2 \%$ \\
Adult & $6.32-6.44$ & $6.38 \pm 0.036$ & 0.0040 & 0.88 & $+2.4 \%$ \\
\hline
\end{tabular}

Table 5

Incus: total width of ossicle $(\mathrm{mm})$

\begin{tabular}{lccccc}
\hline Group & Range & Mean \pm SD & TEM & R & $\%$ change \\
\hline I & $4.30-4.46$ & $4.38 \pm 0.02$ & 0.0066 & 0.66 & $+3.42 \%$ \\
II & $4.51-4.55$ & $4.53 \pm 0.016$ & 0.0020 & 0.87 & $+1.55 \%$ \\
Adult & $4.54-4.64$ & $4.60 \pm 0.031$ & 0.0033 & 0.89 & \\
\hline
\end{tabular}

Table 6

Incus: length of long process ( $\mathrm{mm}$ )

\begin{tabular}{lccccc}
\hline Group & Range & Mean \pm SD & TEM & R & $\%$ change \\
\hline I & $4.43-4.50$ & $4.46 \pm 0.024$ & 0.0030 & 0.87 & $+2.01 \%$ \\
II & $4.53-4.58$ & $4.55 \pm 0.021$ & 0.0025 & 0.88 & $+1.54 \%$ \\
Adult & $4.58-4.66$ & $4.62 \pm 0.042$ & 0.0026 & 0.92 & \\
\hline
\end{tabular}

$96.5 \%$ of adult size at 6 th month IUL and $98.4 \%$ at 9 th month IUL.

\section{Stapes (Tables 7-9, Figure 3)}

Length of foot plate showed steady rise with maximum increase between $28-36$ weeks IUL of $+3.3 \%$. This value

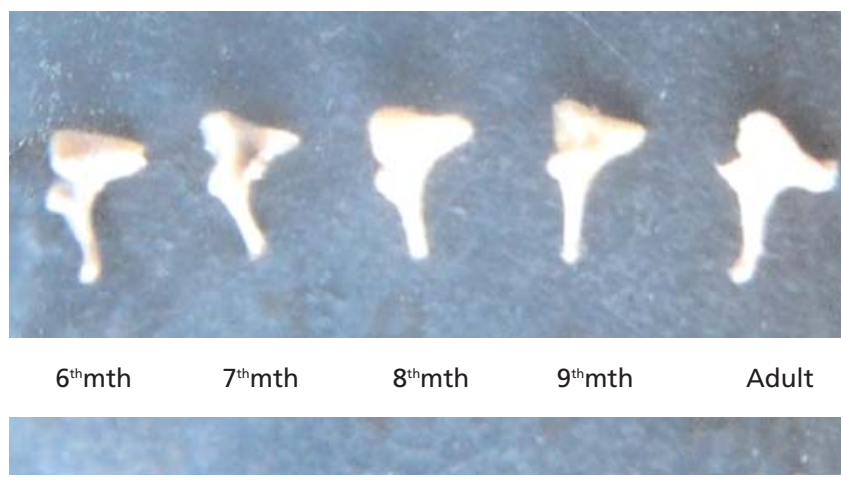

Figure 2. Human fetal incus from 6th month to 9th month IUL and adult incus. 
assumed $94.5 \%$ of adult dimension at 6 th months IUL and $97.6 \%$ at 9 th month IUL.

Width of foot plate showed a positive increase Groups I and II of $+5.5 \%$. This dimension showed $90 \%$ of adult size at 6th month IUL\& $95 \%$ of adult size at 9 th month IUL.

Height of stapes howed an increment of $+4.5 \%$ between 28-36 weeks i.e. Groups I and II. This parameter achieved $84.5 \%$ of adult value at 6 th months IUL and $88.4 \%$ at 9 th month IUL.

\section{Discussion}

The present study on human ear ossicles has given us the knowledge that different parts of each ossicle show different rate of growth during various gestational age periods. The study also showed that increase in size of fetal ossicles occurred evenly, with certain periods of most intensive growth. The study also showed the ossicles at birth are almost equal to adult's size (Figure 4) ${ }^{[17,18]}$ and there are minimal postnatal modifications. ${ }^{[16]}$ The present study has been well compared with other work$\operatorname{ers}^{[2,3,5,7,24-26]}$ and they have also documented this observation, but this study is based on Indian population which is first of its kind, whereas the other workers have done in European races.

Table 10 compares the values taken in some studies of different research groups with our present study at the time of 9th month IUL. This table shows that the values of malleus for length of ossicle and length of handle are very much near to other studies except for Arrensburg and Nathan ${ }^{[3]}$ who have fewer values than the rest, similarly for incus the values for length of ossicle and total width of ossicle are on the lower end in the present study. Regarding the stapes the values are again on the lower side in relation to the height of the ossicle.

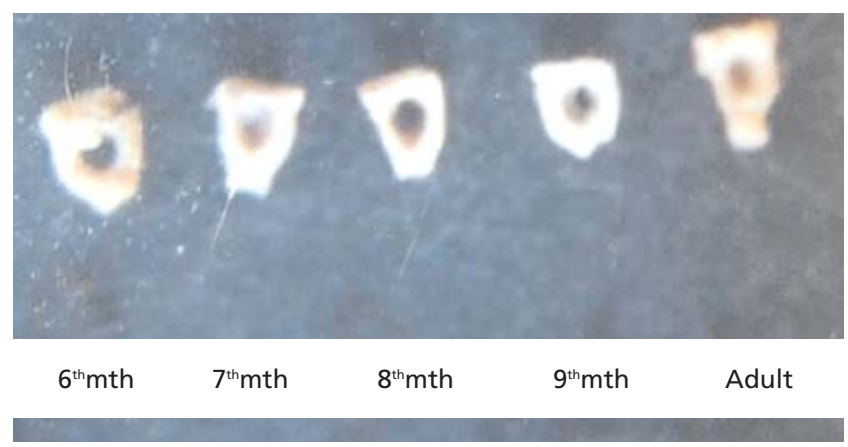

Figure 3. Human fetal stapes from 6th month to 9th month IUL and adult stapes.
Table 7

Stapes: length of footplate $(\mathrm{mm})$

\begin{tabular}{lccccc}
\hline Group & Range & Mean \pm SD & TEM & R & \% change \\
\hline I & $2.74-2.81$ & $2.77 \pm 0.023$ & 0.0029 & 0.87 & \\
II & $2.84-2.89$ & $2.86 \pm 0.017$ & 0.0025 & 0.85 & $+3.3 \%$ \\
Adult & $2.89-3.07$ & $2.93 \pm 0.024$ & 0.0060 & 0.75 & $+2.45 \%$ \\
\hline
\end{tabular}

Table 8

Stapes: width of footplate $(\mathrm{mm})$

\begin{tabular}{lccccc}
\hline Group & Range & Mean \pm SD & TEM & R & $\%$ change \\
\hline I & $1.40-1.48$ & $1.44 \pm 0.025$ & 0.0033 & 0.86 & \\
II & $1.50-1.55$ & $1.52 \pm 0.018$ & 0.0025 & 0.86 & $+5.5 \%$ \\
Adult & $1.55-1.65$ & $1.60 \pm 0.042$ & 0.0033 & 0.92 & $+5.3 \%$ \\
\hline
\end{tabular}

Table 9

Stapes: height of ossicle $(\mathrm{mm})$

\begin{tabular}{lccccc}
\hline Group & Range & Mean \pm SD & TEM & R & $\%$ change \\
\hline I & $2.67-2.73$ & $2.69 \pm 0.022$ & 0.0025 & 0.88 & \\
II & $2.78-2.84$ & $2.81 \pm 0.021$ & 0.0030 & 0.86 & $+4.5 \%$ \\
Adult & $3.12-3.24$ & $3.18 \pm 0.032$ & 0.0040 & 0.87 & $+13.1 \%$ \\
\hline
\end{tabular}

Hence this study assumes much importance in the field of morphometry of ossicles in Indian scenario as morphological variations of ossicles related to race has been documented. ${ }^{[4]}$ The values in the present study were little different in relation to incus and stapes although quite similar for malleus as Indian population has dolichocephalic skulls while European population has

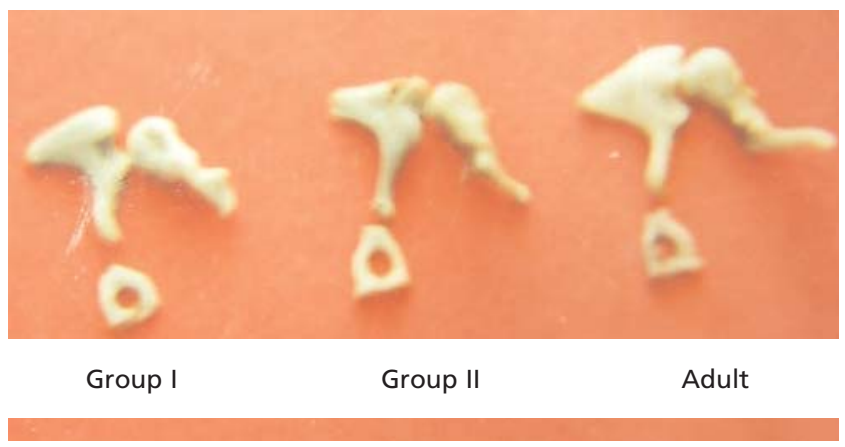

Figure 4. Set of ear ossicles of Groups I and II, and adult ossicles. 
Table 10

Morphometric data of middle ear ossicles from present and some previous studies at the time of 9th month IUL (mm).

\begin{tabular}{|c|c|c|c|c|c|c|c|c|c|}
\hline Parameter & $\begin{array}{c}\text { Present } \\
\text { data }\end{array}$ & $\begin{array}{l}\text { Unur } \\
\text { et al., } \\
2002^{[2]}\end{array}$ & $\begin{array}{c}\text { Bouchet and } \\
\text { and Giraut, } \\
1968^{[24]}\end{array}$ & $\begin{array}{l}\text { Masali, } \\
1968^{[25]}\end{array}$ & $\begin{array}{c}\text { Harada } \\
\text { and Ishii, } \\
1972^{[7]}\end{array}$ & $\begin{array}{c}\text { Arrensburg\& } \\
\text { Nathan, } \\
1972^{[3]}\end{array}$ & $\begin{array}{c}\text { Arrensburg } \\
\text { et al., } \\
1981^{[26]}\end{array}$ & $\begin{array}{l}\text { Aycan } \\
\text { et al., } \\
1990^{[5]}\end{array}$ & $\begin{array}{l}\text { Unur } \\
\text { et al., } \\
1993^{[27]}\end{array}$ \\
\hline \multicolumn{10}{|l|}{ Malleus } \\
\hline Length of ossicle & 7.86 & 7.7 & 7.9 & 7.6 & 8.0 & 7.3 & 7.8 & 8.1 & - \\
\hline Length of handle & 4.53 & 4.7 & 4.7 & 4.6 & 4.2 & 3.5 & 4.4 & 4.9 & - \\
\hline Diameter of head & 2.34 & - & - & - & - & - & - & - & - \\
\hline \multicolumn{10}{|l|}{ Incus } \\
\hline Length of ossicle & 6.23 & 6.5 & 6.5 & 6.4 & 6.8 & 6.8 & 6.4 & - & 6.7 \\
\hline Total width of ossicle & 4.53 & 4.9 & 5.1 & 4.8 & 4.8 & 5.1 & 5.1 & - & 5.1 \\
\hline Length of long process & 4.55 & - & - & - & - & - & - & - & - \\
\hline \multicolumn{10}{|l|}{ Stapes } \\
\hline Height of ossicle & 2.81 & 3.2 & 3.5 & - & - & - & 3.2 & - & - \\
\hline Length of base of footplate & 2.86 & 2.6 & - & - & - & - & 2.8 & - & - \\
\hline Width of base of footplate & 1.52 & 1.3 & - & - & - & - & 1.3 & - & - \\
\hline
\end{tabular}

mesaticephalic skulls. ${ }^{[15]}$ At the same time auditory ossicular dimensions can be used for medicolegal practice have been stated. ${ }^{[2]}$ However, it is possible that the development of bone mass of ossicles may not have been completed during fetal life as has been documented. ${ }^{[19]}$ The most important aspect of this study is that the fetal ossicles can be used as prosthesis or homografts in adults suffering from otosclerosis and ossicular chain malformations, as they have assumed adult dimensions in the last trimester of pregnancy and the post-natal modifications are minimal. ${ }^{[16]}$

\section{References}

1. Williams PL, Bannister LH, Berry MM, et al. (eds.) Gray's Anatomy. 38th ed. Edinburgh: Churchill Livingstone; 1999. p. $355-8$.

2. Unur E, Ulger H, Ekinci N. Morphometrical and morphological variations of middle ear ossicles in the newborn. Erciyes Medical Journal 2002;24:57-63.

3. Arensburg B, Nathan H. Observations on a notch in the short (superior or posterior) process of the incus. Acta Anat (Basel) 1971;78:84-90.

4. Sarrat R, Torres A, Guzman AG, Lostalé F, Whyte J. Functional structure of human auditory ossicles. Acta Anat (Basel) 1992;144: 189-95.

5. Aycan K, Unur E, Bozkır MG. Anatomical study of malleus. Journal of Health Sciences 1990;1:152-8.

6. Hough JV. Congenital malformations of the middle ear. Arch Otolaryngol 1963;78:335-43.

7. Harada $\mathrm{O}$, Ishii $\mathrm{H}$. The condition of the auditory ossicles in microtia: findings in 57 middle ear operations. Plast Reconst Surg 1972;50:48-53.

8. Nomura Y, Nagao Y, Fukaya T. Anomalies of the middle ear. Laryngoscope 1988; 98:390-3
9. Causins VC, Milton CM. Congenital ossicular abnormalities: a review of 68 cases. Am J Otol 1988;9:76-80.

10. Siegert R, Weerda H, Mayer T, Brückmann H. High resolution computerized tomography of middle ear abnormalities. [Article in German] Laryngorhinootologie 1996;75:187-94.

11. Louryan S. Development of auditory ossicles in the human embryo: correlations with data obtained in mice. [Article in French] Bull AssocAnat (Nancy) 1993;77:29-32.

12. Sarrat R, García Guzmán A, Torres A.. Morphological variations of human ossicula tympani. Acta Anat (Basel) 1988;131:146-9.

13. Huttenbrik KB. The mechanics and function of the middle ear. Part 1: The ossicular chain and middle ear muscles. [Article in German] Laryngorhinootologie 1992;71:545-51.

14. Beer HJ, Bornitz M, Hardtke HJ, et al. Modeling of components of the middle ear and simulation of their dynamic behavior. Audiol Neurotol 1999;4:156-62.

15. ApoorvaModi, Parikh. Essentials of Forensic Medicine. 3rd ed. 1992. p. 80-2.

16. Lasky LE, Williams AL. Development of auditory system from conception to term. NeoReviews 2005;6:141-52.

17. Anson BJ, Bast TM. The temporal bone and the ear. Charles. C. Thomas, Springfield: 1949. p. 26-38.

18. Ham AW. Hams Histology. 7th ed. Lippincott; 1974. p. 700.

19. Olszewski J. The morphometry of ear ossicles in human during development. [Article in German] Anat Anz 1990;171:187-91.

20. Barut C, Ertilav H. Guidelines for standard photography in gross and clinical anatomy. Anat Sci Educ 2011; 4:348-56.

21. Ulijaszek SJ, Lourie JA. Anthropometry in health assessment: the importance of measurement error. Coll Antropol 1997;21:429-38.

22. Goto R, Mascie-Taylor CG. Precision of measurement as a component of human variation. J Physiol Anthropol 2007;26:253-6.

23. Weinberg SM, Scott NM, Neiswanger K, Marazita M. Intraobserver error associated with measurements of the hand. Am J Hum Biol 2005;17:368-71. 
24. Bouchet A, Giraud M. Contrubituon a l'etudemorphologique et radiologique des osseletsdel'ouie. Compterendu de l' Association des Anatomists 53 Congrés 1968;141:588-600.

25. Masali, M., 1968. The ear bones and the vertebral column as indicators of taxonomic and postural distinction among old world primates. In: Chiarelli B, ed. Taxonomy and Phylogeny of Old World Primates with References to the Origin of Man. Torino: Rosenberg and Sellier; 1968. p. 69-94.
26. Arensburg B, Harell M, Nathan H. The human middle ear ossicles,morphometry and taxonomic implications. J Hum Evol 1981;10:199-205.

27. Unur E, Aycan K, Ekinci N, et al. The study of incus from morphometric view. Erciyes Medical Journal 1993;15:16-19.

28. Kosiagina ED, Kosiagin DV. Mathematical relationship between the dimensions of the auditory ossicles and fetal age. [Article in Russian] Arkh Anat Gistol Embriol 1978;74:66-8.

\footnotetext{
Correspondence to: Dr. Gulrez Nadeem, PhD, Assistant Professor College of Dentistry, Ajman University of Science and Technology, Ajman, UAE

Phone: 00971501557935

e-mail: gulreznadeem@yahoo.com

Conflict of interest statement: No conflicts declared.
} 